\title{
GRASS GRUB FROM 450 KM: SATELLITES TO ASSESS DAMAGE ON AN AREA-WIDE SCALE ACROSS NEW ZEALAND
}

\author{
M.R. MCNEILL, T.A. JACKSON and R.J. TOWNSEND \\ AgResearch, Lincoln, Private Bag 4749, Christchurch 8140, New Zealand
}

Corresponding author: mark.mcneill@agresearch.co.nz

Earth observation satellites can be used for determining land use and associated changes over time, soil mapping, crop yields and pest damage. Grass grub (Costelytra zealandica) is widespread across New Zealand with high larval populations causing significant pasture losses. The feasibility of using satellite remote sensing to assist grass grub damage mapping was investigated. Images of Canterbury taken by Landsat 5 and Quickbird 2 were compared to photographs taken from a light aircraft flying over grass grub infested pasture. Coverage per pass and altitude were $185 \mathrm{~km}^{2}$ and $780 \mathrm{~km}$ for Landsat 5 and $16 \mathrm{~km}^{2}$ and $450 \mathrm{~km}$ for Quickbird 2, respectively. However, Quickbird 2 has a multispectral band resolution of $2.5 \mathrm{~m}$ (30 m for Landsat 5), giving a better image at the paddock scale for identifying grass grub damage, which compared well with aircraft-acquired photographs. Challenges associated with satellite imagery include excessive cloud cover, sun angle in relation to season, calibration of satellite image to pest damage, the ability to obtain near real-time images and the requirement to task the satellite to acquire images over a particular area. A government backed initiative to use high-medium resolution $(2.5-10 \mathrm{~m})$ satellite services to systematically collect images of the country offers further opportunity to use satellites for insect and disease detection.

\section{INVESTIGATING THE CAUSE OF 'LOCALISED DRY SPOTS' AND PASTURE DAMAGE IN HAWKE'S BAY HILL COUNTRY - ARE MEALYBUG BALANOCOCCUS POAE/RHIZOECUS SPP. OR ROOT APHID APLONEURA LENTISCI IMPLICATED?}

\author{
M.W.A. SLAY ${ }^{1}$ and L. MACGILLIVRAY ${ }^{2}$ \\ ${ }^{1}$ Homelea Limited, Shanley Road, RD 9, Hastings \\ ${ }^{2}$ Tawa Hills Station, Maraetotara, RD 12, Havelock North
}

Corresponding author: slay@farmer.net.nz

Farmers in Hawke's Bay are concerned at the widespread increase in localised dry spots (LDS) and associated losses in pasture production. Occurrence is predominantly in high altitude/high rainfall older hill country and most obvious in summer. Mealybug/root aphid in LDS is considered a possible explanation for the damage. LDS have a negative effect on pasture production in autumn, winter and spring (estimated at 30\%). In summer, two LDS areas and adjacent 'green' pasture were monitored. Mealybug/root aphid presence, soil moisture, soil nutrient status, $\mathrm{C} / \mathrm{N}$ ratio and organic carbon levels were determined. In autumn, mealy bug population was assessed in a typical old pasture. Populations of mealybug at the two LSD/green areas gave contrasting results with a maximum of $2138 / \mathrm{m}^{2}$ in 'green' pasture. Soil was $30 \%$ drier in LDS and there was little difference in soil nutrient levels or $\mathrm{C} / \mathrm{N}$ ratio. In the old pasture, mealybug populations $\left(371 / \mathrm{m}^{2}\right.$ (range 454-306/ $\left.\mathrm{m}^{2}\right)$ ) were associated with the browntop component of the sward (79\%). It was concluded current pasture damage was not commensurate with mealybug/root aphid per se. Previous populations of mealybug/root aphid (wax deposits) and/or other factors (hydrophobic soil) causing apparent soil water repellency were not dismissed as causes of LDS. 